\title{
73. THE AGES OF SEDIMENTS RECOVERED FROM DSDP LEGS 1-4, 10-15, AND 36-53 (ATLANTIC, GULF OF MEXICO, CARIBBEAN, MEDITERRANEAN, AND BLACK SEA)
}

\author{
Hans M. Bolli, Department of Geology, Swiss Federal Institute of Technology, Zürich, and University of Zurich, \\ Switzerland
}

\begin{abstract}
The ages of the sediments recovered from 187 sites drilled during DSDP Legs 1 to 4, 10 to 15 , and 36 to 53 in the Atlantic, Gulf of Mexico, Caribbean, Mediterranean, and Black Sea are plotted in the columnar sections of five figures. Stratigraphic gaps occurring in sedimentary sequences are shown to be the result of either intervals not cored (C), hiatuses $(\mathrm{H})$, or both $(\mathrm{CH})$. The letter $\mathrm{B}$ at the bottom of a section indicates that basement has been reached. The degree of accuracy of the age determinations is also indicated. The purpose of this presentation is to provide quick reference of these data for all the sites drilled in the Atlantic and adjacent seas.
\end{abstract}

\section{INTRODUCTION}

With Site 418 of Leg 53, DSDP completed the three phases of drilling by Glomar Challenger in the Atlantic Ocean and adjacent seas carried out during Legs 1 to 4,10 to 15 , and 36 to 53 . Altogether, 192 sites were drilled or attempted during these legs: Sites 1 to 31 on Legs 1 to 4 , Sites 85 to 154 on Legs 10 to 15 , and Sites 316 to 418 on Legs 36 to 53. Of these, the following five were attempted but finally not drilled for technical reasons: Sites 109 and 110 (U.S. Continental Rise), Site 145 (Caribbean Sea), Site 351 (Norwegian Sea), and Site 414 (Cruiser-Irwing Seamount). The geographical position of each site is shown on Figure 1.

\section{RESULTS AND DISCUSSION}

It seems opportune at this point to summarize briefly some of the principal results of this drilling campaign. Sediment ages observed for each of the drilled sites are plotted in columnar sections in Figures 2 through 6 in such a way that quick reference can be made by regarding age intervals present and recovered. By arranging the sites in a sequence based on geographical area, general trends in sediment ages and possible hiatuses in given areas become relatively apparent. However, one should keep in mind that such trends may be strongly masked by those sites where the sedimentary sequence was not completely penetrated down to basement, or which were not continuously cored or had poor recovery. In addition to the sediment ages for each site, the degree of accuracy in age determination is indicated by four different symbols (see legend). Apparent stratigraphic gaps in the column caused (at least in part) by discontinuous coring are shown by an $\mathrm{H}$. $\mathrm{CH}$ indicates intervals where in addition to discontinuous coring, an actual hiatus is regarded as responsible for the stratigraphic gap. The letter B at the base of a section indicates that basement was reached.
The data presented here are taken from the Initial Report volumes that were published at the time of preparing this paper, i.e., up to Volume 42, Part 2. The information on ages from the later sites (Legs 43 to 53) is based primarily on the Initial Core Description volumes. Since it was not possible to draw all the information directly from the published Initial Report volumes, in some instances ages shown here for sites from these later legs may differ slightly from those in the published volumes. These data can be corrected if necessary to reflect subsequent changes appearing in the Initial Reports.

Not shown on the figures are intervals with discontinuous coring within all or part of a period or stage, thicknesses of sedimentary sequences, lithology, core recovery, or fossils used for age determination. This supplemental, detailed information has to be obtained directly from the core barrel sheets in the Initial Report volumes.

Ages are taken from the core barrel sheets at the end of each site report. They are largely based on planktonic foraminiferal or calcareous nannoplankton data. Only occasionally are ages derived from other microfossils such as radiolarians, palynomorphs, diatoms, and fish denticles. In some cases, ages given on core barrel sheets differ slightly from those shown in the respective site reports or individual reports in the volumes.

When comparing ages of different legs, one has to be aware that these may be based on somewhat differing zonal schemes, both for planktonic foraminifers and calcareous nannoplankton, and occasionally for radiolarians. However, such age differences are minimal and seldom cross period or stage limits. There is also no uniformity in the individual volumes in the subdivision of periods within the Tertiary and of stages in the Cretaceous and Jurassic. In the Tertiary, it is particularly the Pliocene, Oligocene, and Paleocene, and in the Cretaceous, the Maestrichtian and Albian which in some volumes are subdivided into upper, middle, and lower, and in others only into upper and lower. In some of 


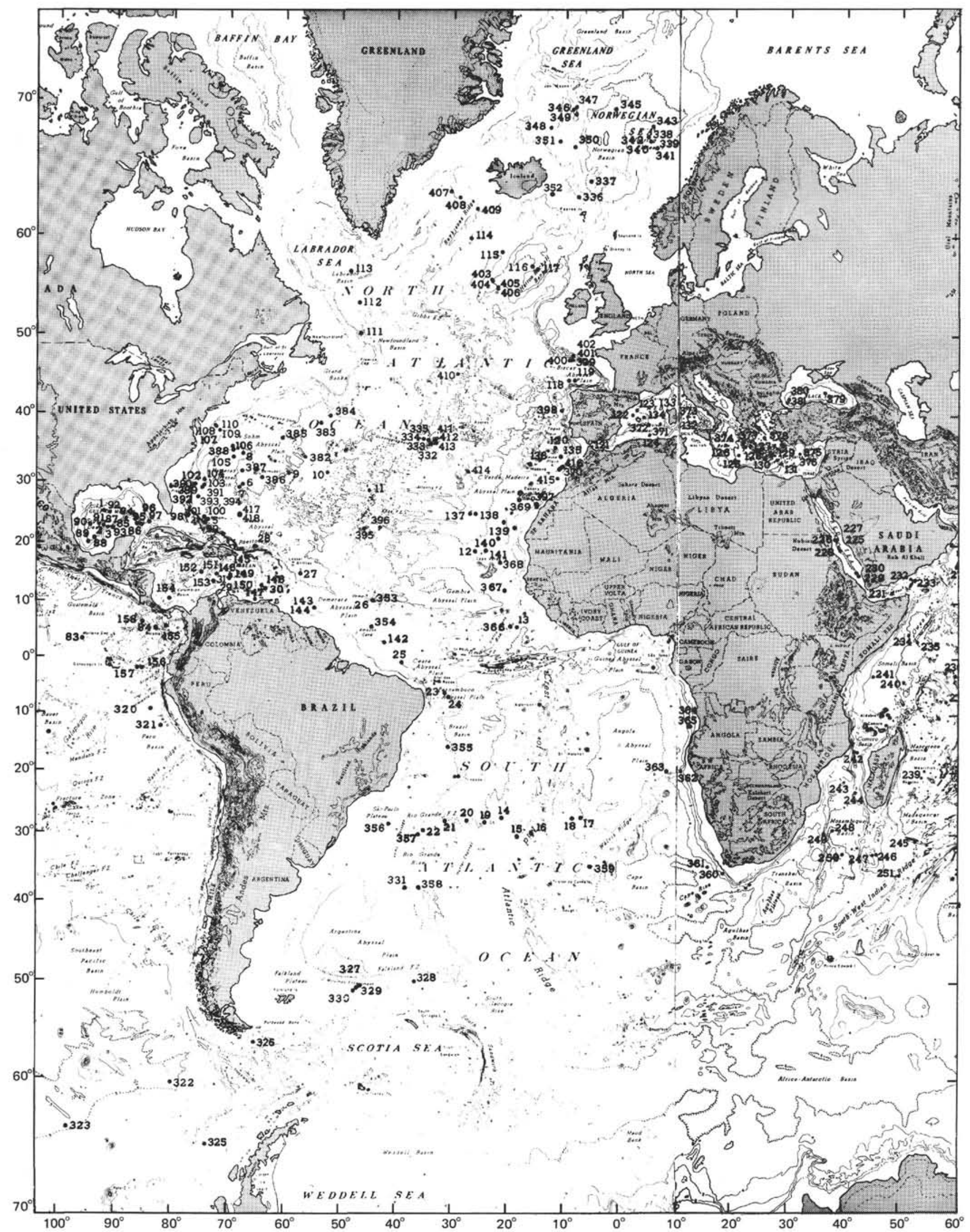

Figure 1. Location of DSDP sites drilled in the Atlantic, Gulf of Mexico, Caribbean, Mediterranean, and Black Sea. 
the reports, the Pleistocene is not subdivided, while in others a lower and upper Pleistocene are distinguished. In exceptional cases, a middle Pleistocene may also be recognized.

The subdivision of Cretaceous stages into upper, middle, and lower, or upper and lower, is restricted in most volumes to the Upper Cretaceous and late Lower Cretaceous (Maestrichtian to Aptian), whereas the early Lower Cretaceous (Barremian to Berriasian) and the Upper Jurassic (Tithonian to Oxfordian) received no further subdivision. Exceptions to this are found however in some of the later legs $(43,44,47$, 48 , and 50). Because final data on these Lower Cretaceous/Upper Jurassic stage subdivisions were not available at the time of the original preparation of the tables, they had to be omitted. Reference to such subdivisions therefore is made to the core barrel sheets as published in the Initial Report volumes of these later legs.

The basic layout of the figures follows that applied to the Indian Ocean sites in Bolli and Saunders (1977). To avoid lengthy foldouts, the data are presented on five separate figures. Figure 2 contains the sites of the South Atlantic south of the equator; Figure 3, those from the North Atlantic north of $40^{\circ} \mathrm{N}$, and Figure 4 shows the North Atlantic sites between the equator and $40^{\circ} \mathrm{N}$. The Gulf of Mexico and the Caribbean are plotted on Figure 5, while those drilled in the Mediterranean and the Black Sea appear on Figure 6.

The sequence of the individual sites in each geographic area is clockwise and runs from west to east. For the South Atlantic (Figure 2), it begins at the Drake Passage near the southernmost tip of South America, moves north into the
Brazil Basin, then across the Mid-Atlantic Ridge to the eastern Atlantic Angola Basin, and from there south via the Walvis Ridge into the Cape Basin. For the North Atlantic north of $40^{\circ} \mathrm{N}$ (Figure 3 ), the sequence begins with the sites drilled in the Newfoundland-Labrador basins and continues from there to the Mid-Atlantic-Reykjanes Ridge and the Norwegian Sea, into the eastern Atlantic Iceland Basin, the Rockall-Hatton banks, the Bay of Biscay, and finally into the Iberia Abyssal Plain. In the Central North Atlantic (Figure 4), the sequence begins in the Ceara Abyssal Plain off northern Brazil, moves northward to the Bahamas area, then northwestward along the U.S. Continental Rise and the Bermuda Rise, then eastward to the Mid-Atlantic Ridge and the sites west of Morocco and the Spanish Sahara, and finally to the sites around the Cap Verde Islands and the Sierra Leone Rise. In Figure 5, the Gulf of Mexico sites are listed from the Mexico-Texas Continental Rise to the Sigsbee Basin, the Campeche Scarp, and the Florida Strait. The Caribbean sites are plotted from the Colombia Basin in the west to the Aves Ridge in the east. The Mediterranean and Black Sea sites in Figure 6 also appear in an west/east sequence, with those from the Mediterranean ranging from the Alboran Basin south of Malaga to the Florence Rise west of Cyprus.

\section{REFERENCE}

Bolli, H.M. and Saunders, J.B., 1977. Introduction to stratigraphy and paleontology. Indian Ocean geology and biostratigraphy, Am. Geophys. Union, p. 311-324. 


\section{LEGEND FOR FIGURES 2-6}

Subdivision of Epoch or Stage into upper (U), middle (M) and lower (L), e. g. upper Miocene, lower Campanian

Epoch or Stage without subdivision into upper, middle, lower, e. g. Oligocene, Albian

Age determination includes all or part of two adjacent Epochs or Stages, e. g. Oligocene to Eocene, lower Maestrichtian or Campanian

Age determination includes all or part of more than two Epochs or Stages, e. g. Lower Cretaceous, upper Santonian to middle Albian

Middle part of an Epoch or Stage not recognized but apparently no hiatus present. Applies mostly to Pliocene, occasionally to other Periods or Stages

? All or part of Period(s) or Stage(s) reported as only questionably present

Absence of Period or Stage caused at least in part by discontinuous coring

Absence of all or part of Period or Stage caused by hiatus (within continuously cored intervals)

B Basement reached 


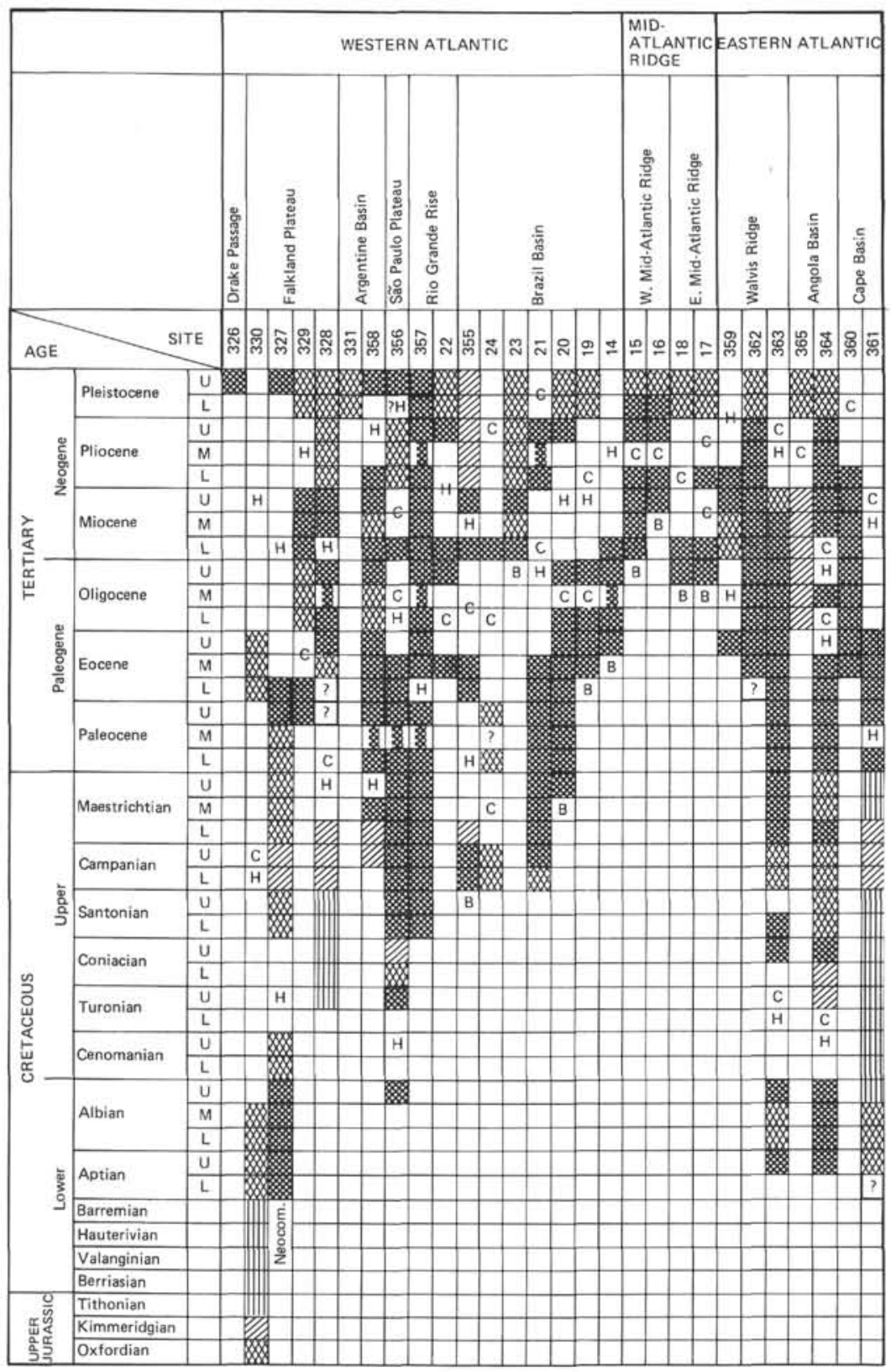

Figure 2. South Atlantic. 


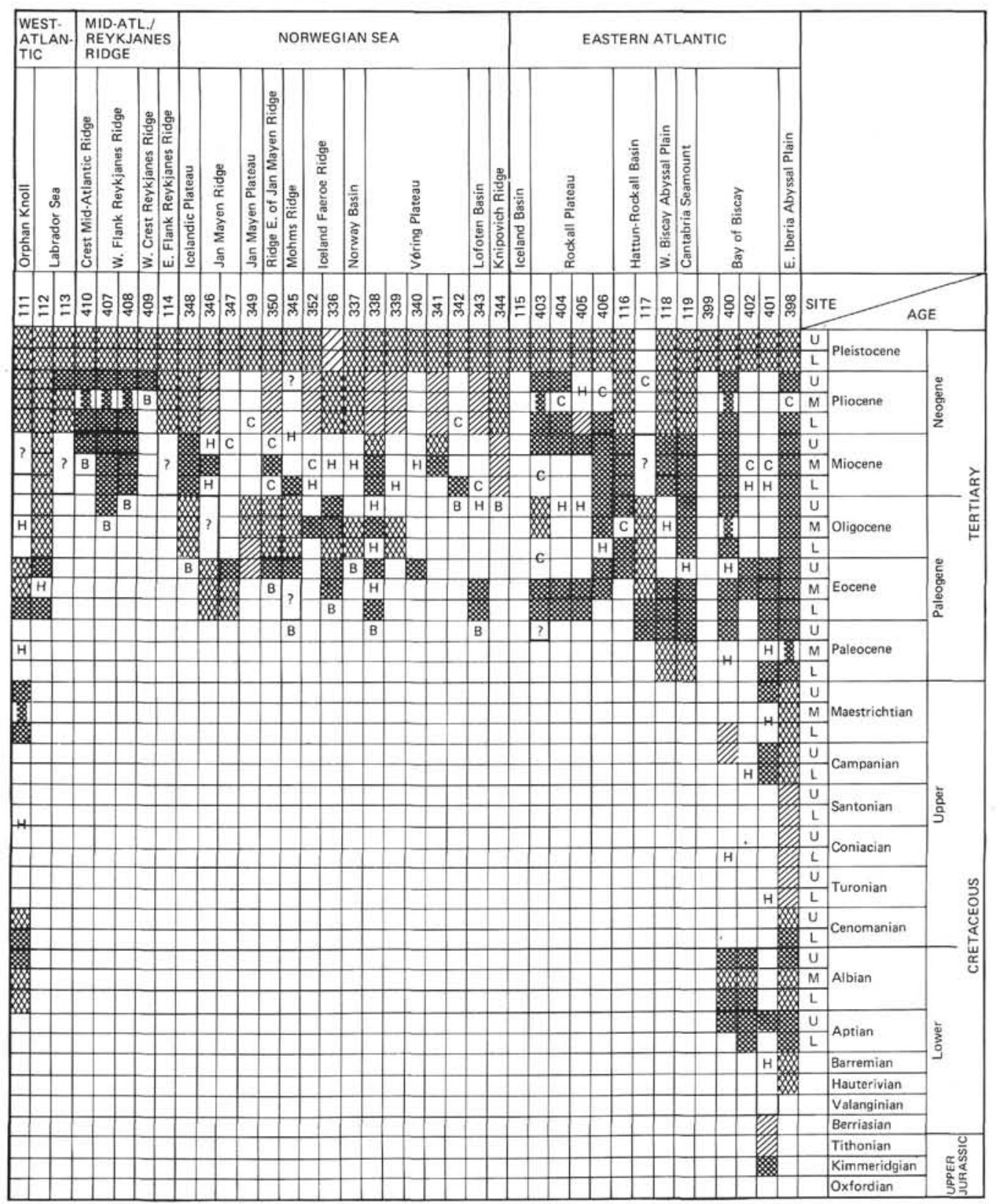

Figure 3. North Atlantic (north of $40^{\circ}$ ). 


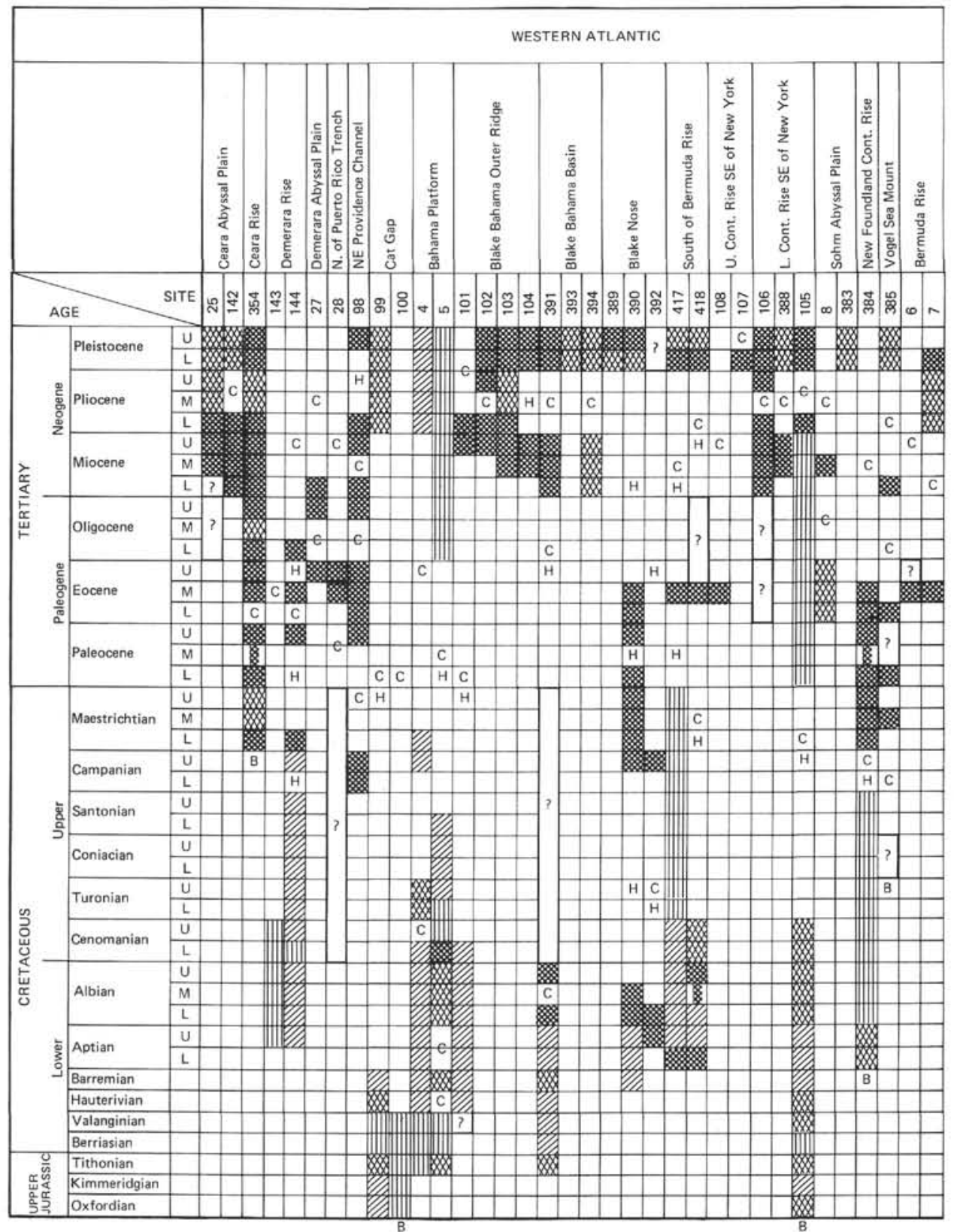

Figure 4. North Atlantic $\left(0^{\circ}\right.$ to $\left.40^{\circ} \mathrm{N}\right)$. 


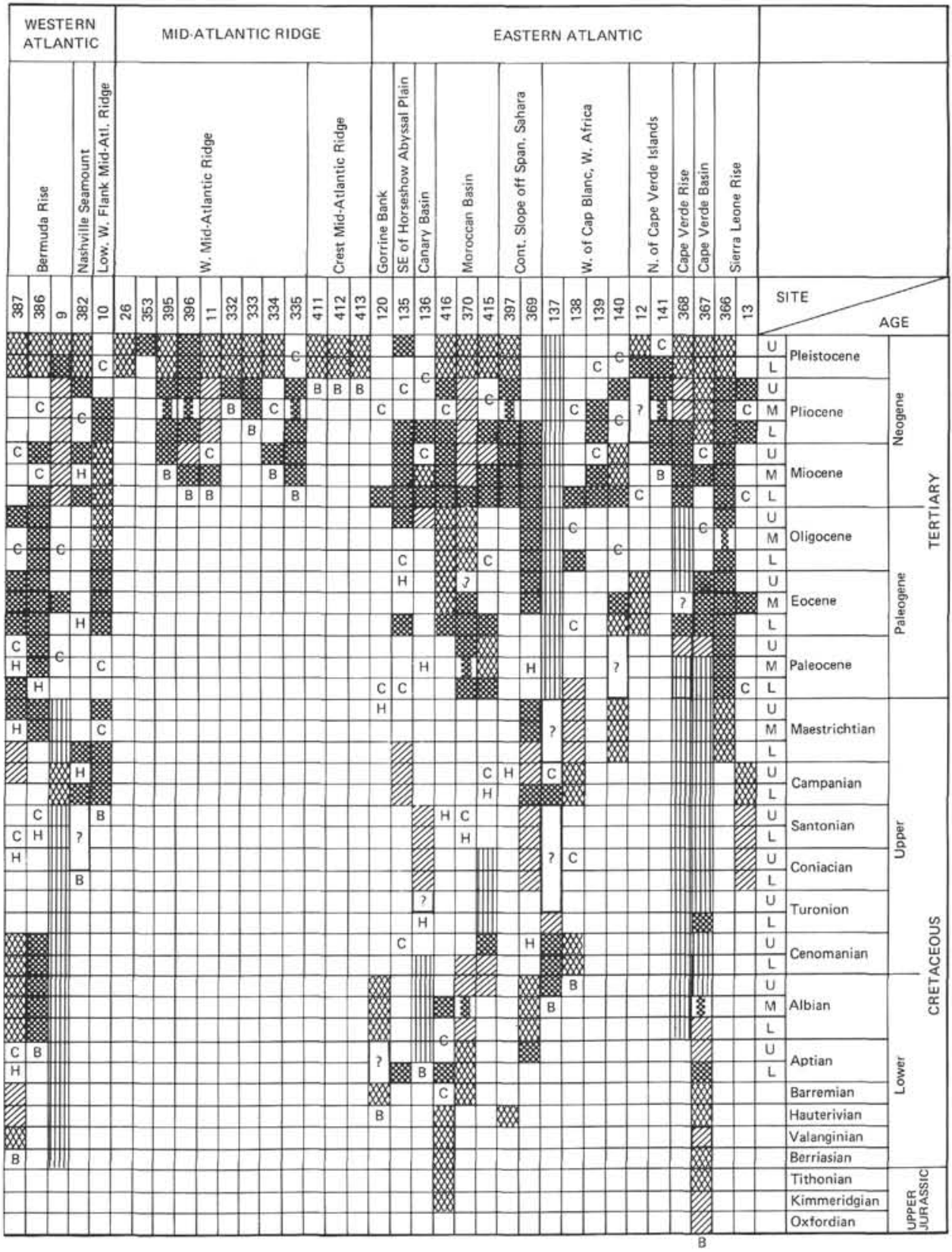

Figure 4. (Continued.) 


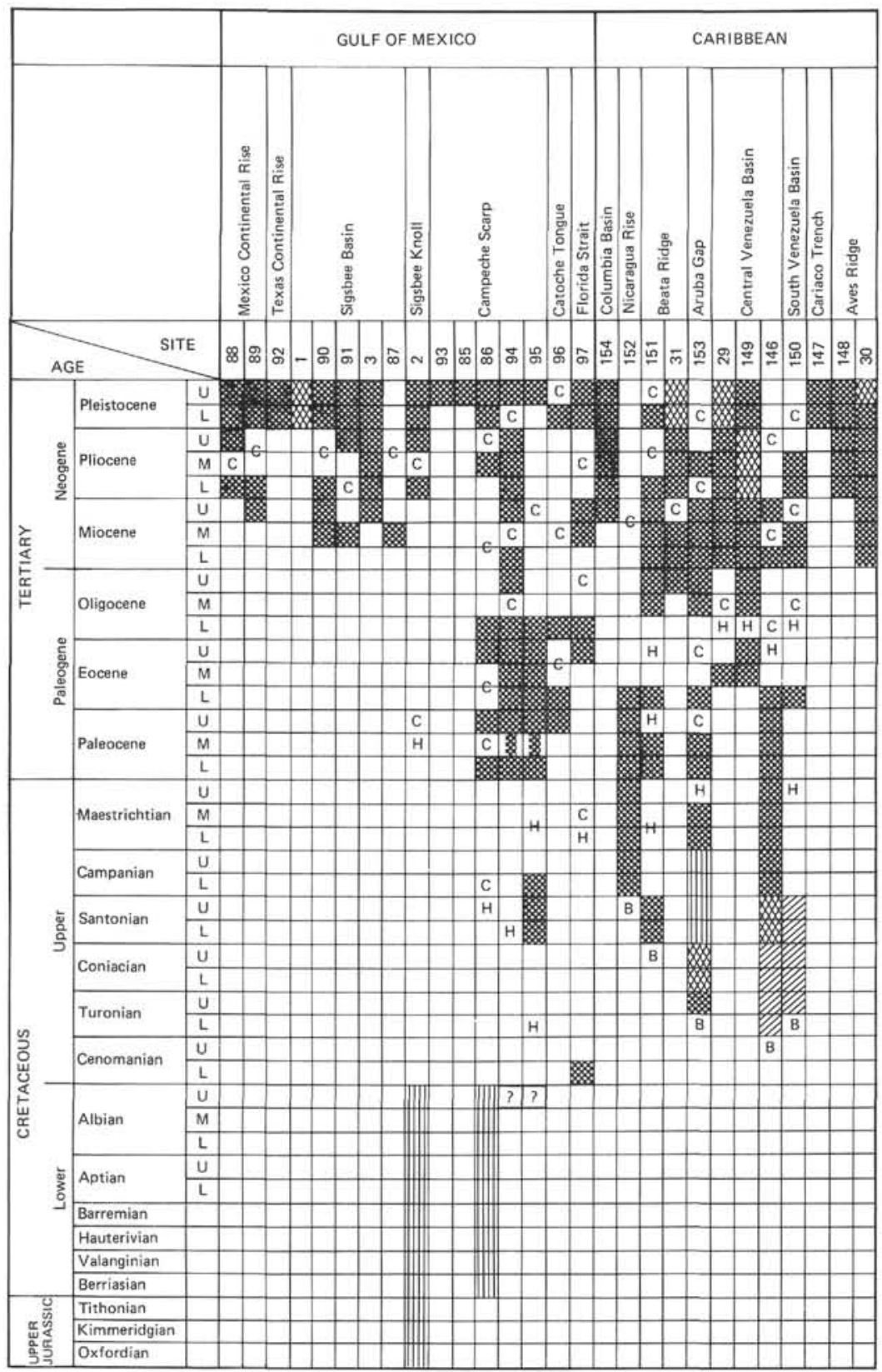

Figure 5. Gulf of Mexico and Caribbean. 
H. M. BOLLI

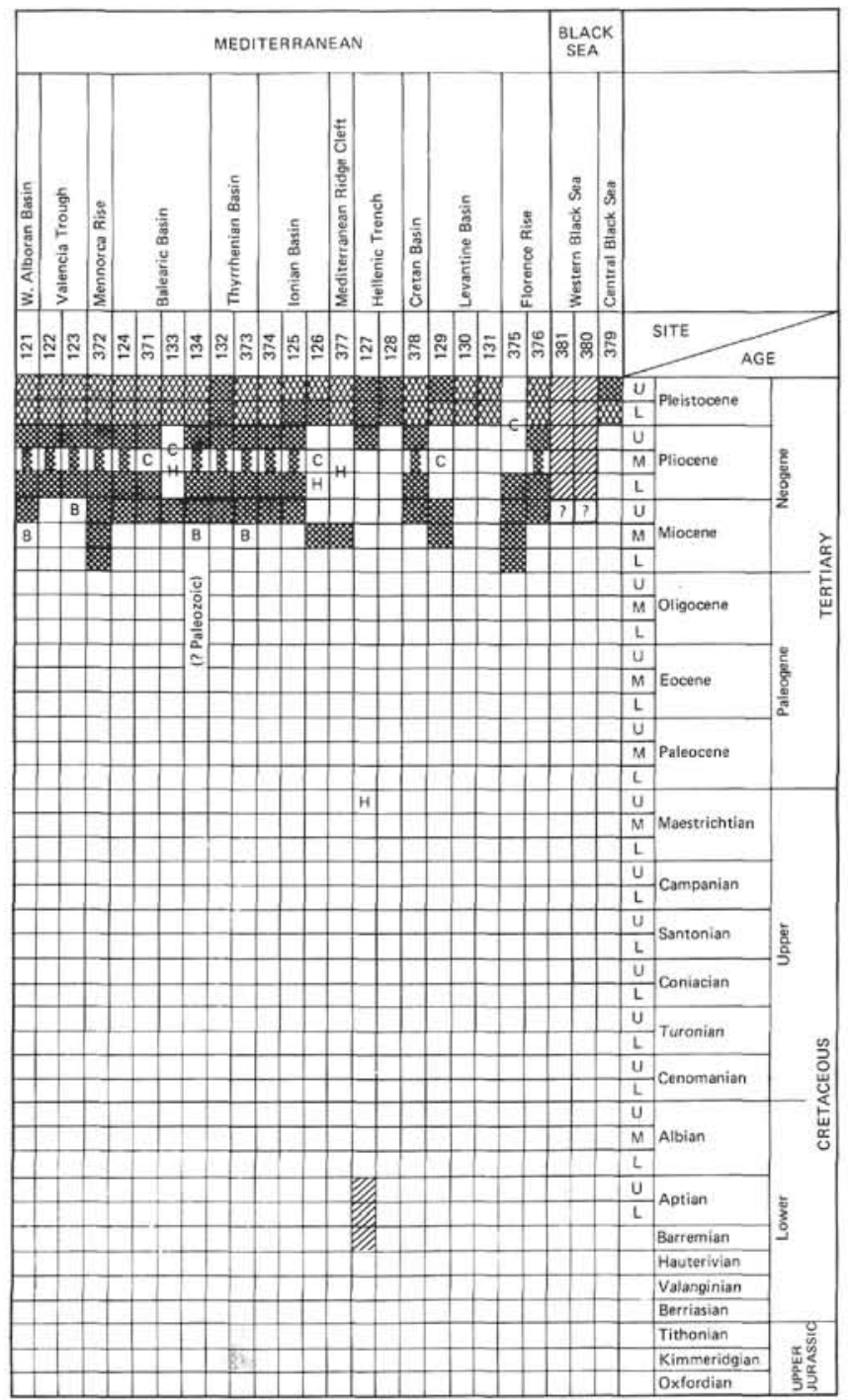

Figure 6. Mediterranean and Black Sea. 